\title{
EGFR as a therapeutic target for human, canine, and mouse ACTH-secreting pituitary adenomas
}

\author{
Hidenori Fukuoka, ${ }^{1}$ Odelia Cooper, ${ }^{1}$ Anat Ben-Shlomo, ${ }^{1}$ Adam Mamelak, ${ }^{1,2}$ \\ Song-Guang Ren, ${ }^{1}$ Dave Bruyette, ${ }^{3}$ and Shlomo Melmed ${ }^{1}$ \\ ${ }^{1}$ Pituitary Center, Department of Medicine, and 2Department of Neurosurgery, Cedars-Sinai Medical Center, Los Angeles, California, USA. \\ ${ }^{3} \mathrm{VCA}$ West Los Angeles Animal Hospital, Los Angeles, California, USA.
}

\begin{abstract}
Cushing disease is a condition in which the pituitary gland releases excessive adrenocorticotropic hormone (ACTH) as a result of an adenoma arising from the ACTH-secreting cells in the anterior pituitary. ACTH-secreting pituitary adenomas lead to hypercortisolemia and cause significant morbidity and mortality. Pituitarydirected medications are mostly ineffective, and new treatment options are needed. As these tumors express EGFR, we tested whether EGFR might provide a therapeutic target for Cushing disease. Here, we show that in surgically resected human and canine corticotroph cultured tumors, blocking EGFR suppressed expression of proopiomelanocortin $(P O M C)$, the ACTH precursor. In mouse corticotroph EGFR transfectants, ACTH secretion was enhanced, and EGF increased Pomc promoter activity, an effect that was dependent on MAPK. Blocking EGFR activity with gefitinib, an EGFR tyrosine kinase inhibitor, attenuated Pomc expression, inhibited corticotroph tumor cell proliferation, and induced apoptosis. As predominantly nuclear EGFR expression was observed in canine and human corticotroph tumors, we preferentially targeted EGFR to mouse corticotroph cell nuclei, which resulted in higher Pomc expression and ACTH secretion, both of which were inhibited by gefitinib. In athymic nude mice, EGFR overexpression enhanced the growth of explanted ACTH-secreting tumors and further elevated serum corticosterone levels. Gefitinib treatment decreased both tumor size and corticosterone levels; it also reversed signs of hypercortisolemia, including elevated glucose levels and excess omental fat. These results indicate that inhibiting EGFR signaling may be a novel strategy for treating Cushing disease.
\end{abstract}

\section{Introduction}

Pituitary tumors, accounting for approximately $15 \%$ of intracranial tumors, are invariably benign monoclonal adenomas with excessive hormone secretion and/or tumor mass effects compressing vital structures (1). Adrenocorticotropic hormone-secreting (ACTHsecreting) tumors arising from pituitary corticotroph cells exhibit substantial morbidity and cause adrenal hypercortisolemia that results in osteoporosis, infections, psychiatric disorders, muscle atrophy, fat accumulation, hypertension, hyperglycemia, and ultimately death (2). The clinical syndrome of hypercortisolemia caused by ACTH-secreting pituitary tumor is known as Cushing disease.

No drug that effectively targets ACTH-secreting pituitary adenomas is currently approved $(3,4)$. Agents that inhibit adrenal cortisol synthesis have limited use due to side effects, moderate efficacy, and inability to target the pituitary tumor. Optimal treatment requires surgical adenoma resection, with initial remission rates achieved by experienced pituitary surgeons ranging $65 \%-90 \%$ for microadenomas, and less than $65 \%$ for macroadenomas (3). Postoperative recurrence rates at 10 years are $10 \%-20 \%$ for microadenomas and up to $45 \%$ for macroadenomas (3). Surgical cure is further challenged by the fact that preoperative pituitary tumor localization may be difficult, even using high-resolution MRI. More than $70 \%$ of ACTH-secreting tumors are less than $10 \mathrm{~mm}$ in size, and up to $50 \%$ of patients have no detectable tumor by MRI (5). Inferior petrosal sinus sampling of ACTH gradients, an invasive angiographic procedure, is frequently needed to confirm

Conflict of interest: The authors have declared that no conflict of interest exists. Citation for this article: J Clin Invest. 2011;121(12):4712-4721. doi:10.1172/JCI60417. the presence of an ACTH-secreting pituitary tumor (6-8). Early results with the somatostatin analog pasireotide or the dopamine agonist cabergoline have shown short-term biochemical control in a minority of patients with Cushing disease $(9,10)$. Long-term side effects and efficacy of these medications in patients with Cushing disease are unknown, and pasireotide predisposes to hyperglycemia development (11). Clinical trials of retinoic acid in canine Cushing disease have shown promise, but have not been extended to human use (12).

EGFR activation, resulting either from mutation or from ligand or receptor overexpression, is associated with a variety of human cancers (13). EGF is a pituitary cell growth factor and also directly induces prolactin synthesis (14). Although approximately $60 \%$ of pituitary tumors - including ACTH-secreting adenomas (40\%-80\%) - express EGFR (15-18), the role of the receptor in tumorigenesis remains unclear. In pituitary corticotroph tumors expressing EGFR, p27 ${ }^{\mathrm{Kip} 1}$, a cyclin-dependent kinase inhibitor, is downregulated (18). Mice with disrupted p27 also develop pituitary tumors mostly expressing proopiomelanocortin (POMC), a precursor protein of ACTH (19-22). We hypothesized that the receptor could be a novel target for therapy of Cushing disease, and therefore tested EGFR signaling in ACTH-secreting pituitary adenomas.

Gefitinib, a tyrosine kinase inhibitor (TKI) targeting the EGFR, blocks activity at the intracellular ATP-binding site of the tyrosine kinase domain (23). Gefitinib exhibits efficacy in treating pulmonary adenocarcinoma, especially in female Asian nonsmokers with deletion mutants of exon 19 (del746_A750) or point mutations of exon 21 (L858R) (24). Gefitinib is also effective in other cancers that overexpress EGFR (either WT or mutants; refs. 25, 26). 
A

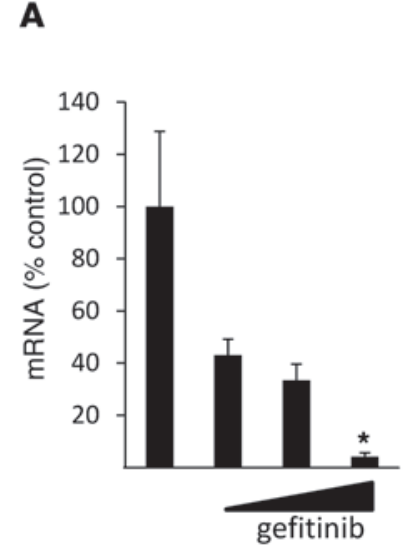

B $=\operatorname{Dog} 1=\operatorname{Dog} 2=\operatorname{Dog} 3=\operatorname{Dog} 4=\operatorname{Dog} 5=\operatorname{Dog} 6$

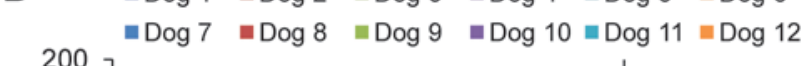

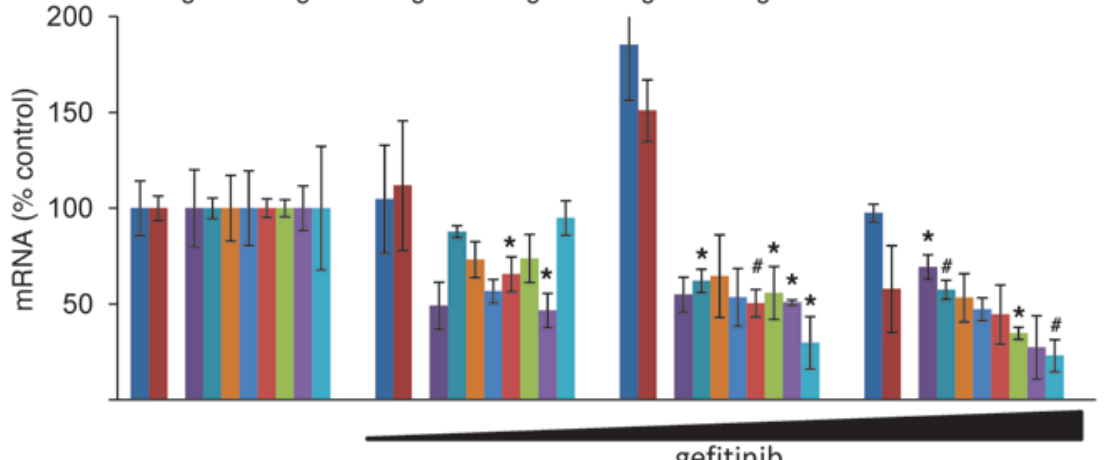

gefitinib
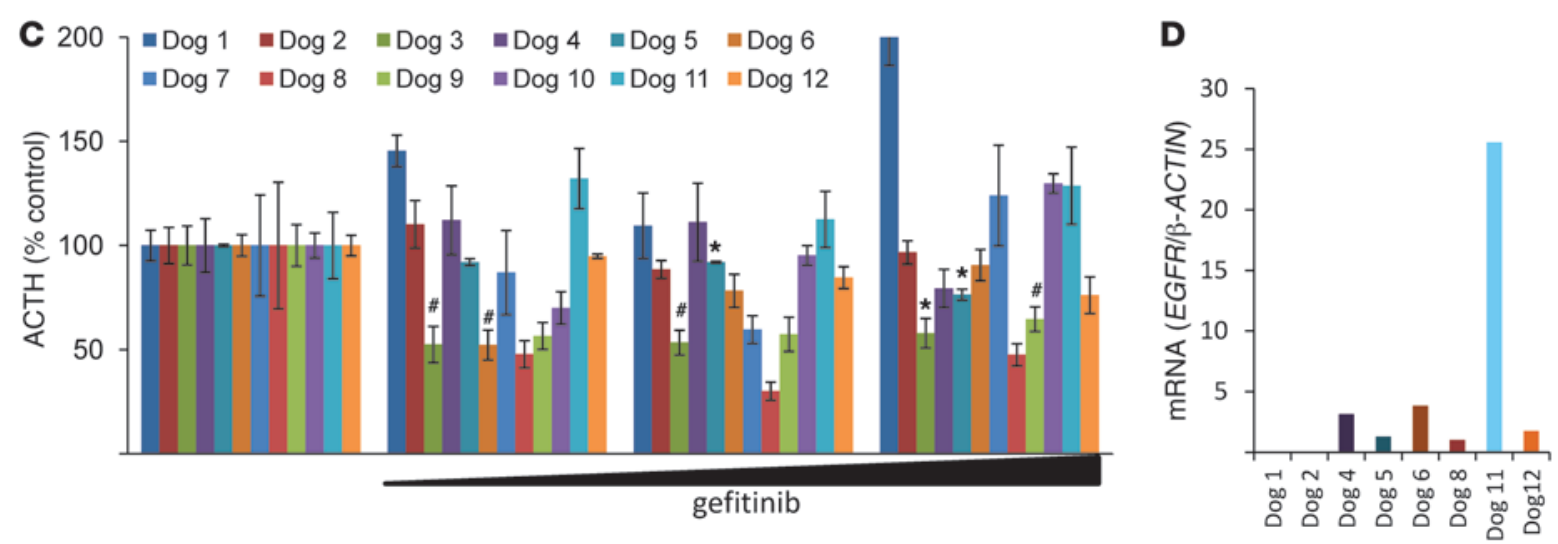

\section{Figure 1}

Effects of gefitinib on human and canine corticotroph adenoma cell cultures. (A) After trans-sphenoidal surgical resection of human ACTH-secreting adenomas, tumor cells were dispersed, cultured, and treated with gefitinib $(0.1-10 \mu \mathrm{M})$ for 24 hours, and human $P O M C$ expression levels were measured by real-time PCR. A representative experiment is shown (normalized by GAPDH). Each bar depicts 5 control replicates and 3 for each dose $(0.1-10 \mu \mathrm{M})$. (B-D) After trans-sphenoidal surgical resection of canine ACTH-secreting adenomas, tumor cells were dispersed, cultured, and treated with gefitinib $(0.1-10 \mu \mathrm{M})$ for 24 hours. (B) Canine POMC expression levels were measured by real-time PCR. A representative experiment is shown (normalized by RPS5). (C) ACTH levels in culture media were measured using RIA. (D) Taqman PCR was performed using a specific canine EGFR probe and normalized by canine $\beta$-ACTIN. Values are mean \pm SEM. ${ }^{*} P<0.05,{ }^{\#} P<0.01$.

Here, we show the functional role of EGFR in human, canine, and murine corticotroph tumors and provide evidence supporting the use of EGFR TKI as a targeted therapy for Cushing disease.

\section{Results}

Gefitinib suppresses human corticotroph adenoma POMC expression. Since human corticotroph adenomas express EGFR, we treated primary cell cultures derived from surgically resected human ACTH-secreting tumors with gefitinib $(0.1-10 \mu \mathrm{M})$ for 24 hours. As tumor cell POMC mRNA expression levels were dose-dependently suppressed by gefitinib ( $95 \%, P<0.05$; Figure $1 \mathrm{~A})$, we reasoned that EGFR inhibition could be a target for suppressing ACTH in corticotroph adenomas.

Effects of gefitinib on ACTH-producing canine pituitary tumor cells. These rarely encountered human adenomas are extremely small, and as minimal tissue is available for biochemical and genetic manipulation, we used canine and murine models that largely recapitulate the human disorder. As Cushing disease is frequently encountered in domestic dogs (27), we cultured cells derived from 12 canine ACTH-secreting pituitary tumors after trans-sphenoidal resection (28). We treated tumor cell cultures derived from 12 different dogs with gefitinib and extracted mRNA from 10 separate tumor cell cultures (excepting dogs 3 and 12, which did not yield sufficient mRNA). In 6 of 10 tumor cell cultures, gefitinib suppressed POMC mRNA levels (up to 70\%), and in 4 of 12 tumor cell cultures, medium ACTH secretion was attenuated by the TKI by up to $60 \%$ (Figure 1, B and C). Thus, 8 of 12 tumor cell cultures were markedly affected by gefitinib. In contrast, in nontumorous primary canine pituitary cell cultures, POMC mRNA expression levels were unaltered by gefitinib (Supplemental Figure 1; available online with this article; doi:10.1172/JCI60417DS1). To confirm canine corticotroph tumor EGFR expression, we performed Taqman PCR using canine-specific EGFR probes and showed that 6 of 8 tumors that responded to gefitinib expressed $E G F R$ (Figure 1D); the 2 tumors that did not express EGFR were nonresponders (dogs 1 and 2), whereas EGFR expression was not able to be assessed in 2 tumors (dogs 7 and 10).

EGFR signaling induces Pomc expression and ACTH secretion via $M A P K$. To investigate the functional role of EGFR in tumorous corticotrophs, we generated stably transfected AtT20 cells, which do not express endogenous EGFR, using a retroviral vector containing EGFRWT cDNA, cDNA of a constitutively active form of 

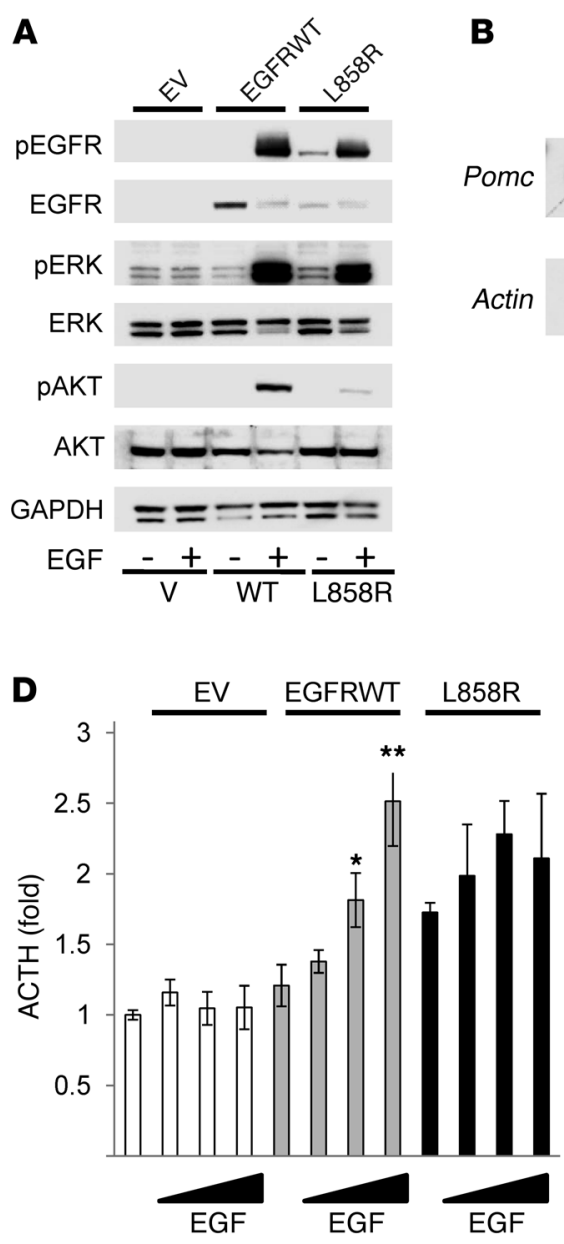

B
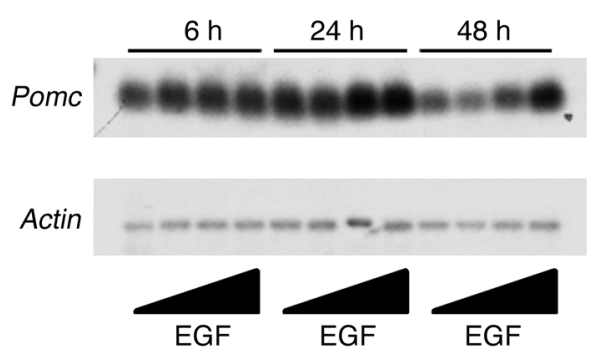

C

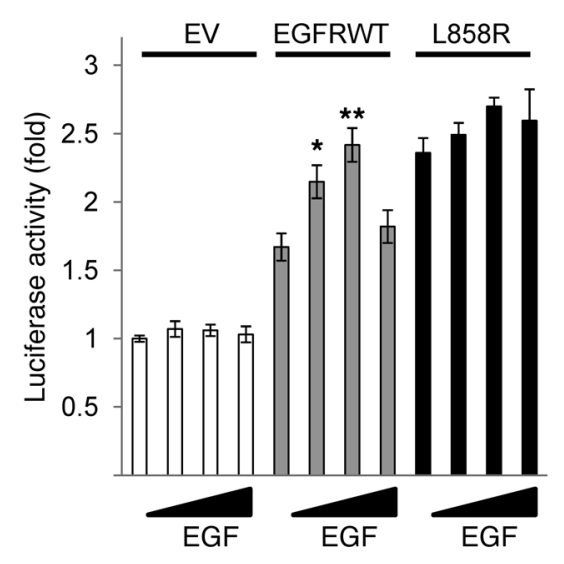

E

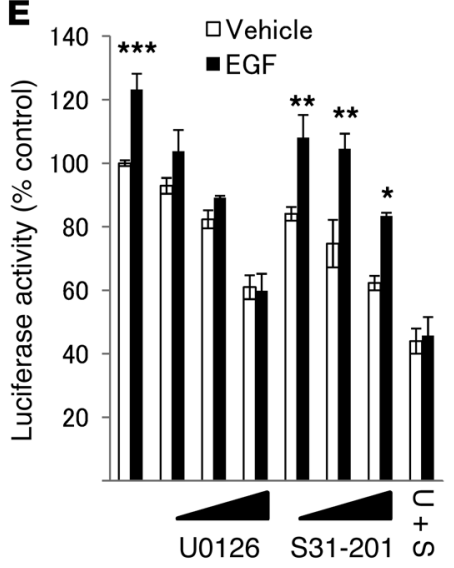

$\mathbf{F}$

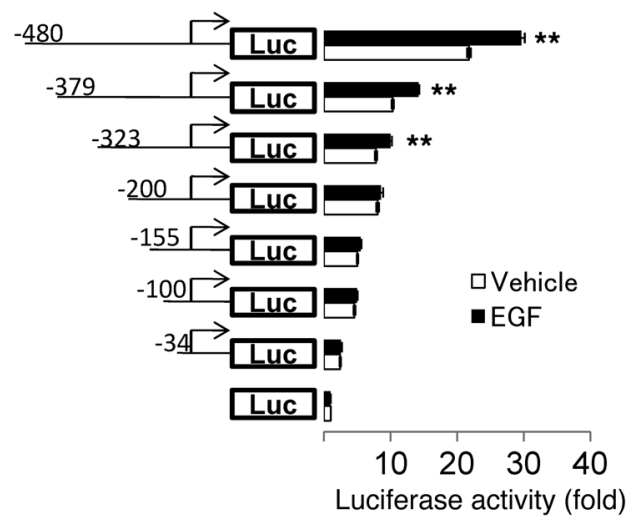

Figure 2

EGFR enhances Pomc mRNA expression and ACTH secretion via MAPK. (A) EGFRWT, L858R, or EV AtT20 cells were treated with 5 nM EGF for 10 minutes, and Western blotting was performed. (B) EGFRWT cells were treated with EGF $(0.5-50 \mathrm{nM})$ for the indicated times, and Northern blotting was performed. (C) EGFRWT, L858R, or EV cells were transfected with Pomc promoter and pRL-TK for 24 hours. After 6 hours of serum deprivation, cells were stimulated with EGF $(0.5-50 \mathrm{nM})$ for 24 hours. (D) EGFRWT, L858R, or EV cells were treated with $5 \mathrm{nM}$ EGF for 24 hours. ACTH secretion in the culture medium was determined by RIA (normalized for cell numbers). (E) EGFRWT cells were transfected with Pomc promoter and pRL-TK for 24 hours. After 6 hours of serum deprivation, cells were treated with $\mathrm{U} 0126(0.1-10 \mu \mathrm{M})$ or/and S31-201 $(10-50 \mu \mathrm{M})$ for 45 minutes prior to induction with $5 \mathrm{nM}$ EGF for 24 hours. (F) EGFRWT cells were transfected with Pomc promoter deletion mutants and pRL-TK for 24 hours. After 6 hours of serum deprivation, cells were stimulated with 5 nM EGF for 24 hours. Values are mean \pm SEM. ${ }^{\star} P<0.05,{ }^{* *} P<0.01,{ }^{* \star *} P<0.05$ vs. respective control (untreated EGFRWT or vehicle). Representative results are from triplicate samples in at least 2 independent experiments.

EGFR (L858R), prevalent in lung cancer $(29,30)$, or empty vector $(\mathrm{EV})$. The respective cells generated are referred to herein as EGFRWT cells, L858R cells, and EV cells. Western blot results showed abundant EGFR protein expression in EGFRWT cells, but not in EV cells (Figure 2A). L858R cells exhibited tyrosine autophosphorylation even without added ligand, while EGF treatment induced receptor phosphorylation in both EGFRWT and L858R transfectants (Figure 2A). MAPK and Akt pathways were activated by EGF in both EGFR transfectants, and effects of added ligand were more pronounced in EGFRWT than in L858R cells. Northern blotting showed that EGF dose-dependently enhanced Pomc expression levels in EGFRWT cells ( 2 -fold, $P<0.05$; Figure $2 \mathrm{~B})$.

Next, we tested regulation of Pomc promoter activity by EGFR. Luciferase expression driven by the Pomc promoter was induced by EGFR overexpression itself (L858R, $\sim 2.5$-fold that of EV; EGFR-
WT, $\sim 1.7$-fold that of EV) and was further enhanced by EGF treatment in EGFRWT transfectants $(\sim 1.5$-fold, $P<0.01)$, but not in L858R transfectants (Figure $2 \mathrm{C}$ ). ACTH secretion to the culture media was enhanced in L858R transfectants $(\sim 1.7$-fold, $P<0.001)$ but not in EGFRWT transfectants, whereas EGF dose-dependently induced ACTH levels only in EGFRWT cells $(\sim 2.5$-fold, $P<0.01$; Figure 2D). Since the Pomc promoter is regulated by MAPK or STAT3 pathways, we used MAPK inhibitor U0126 or STAT3 inhibitor S31-201; Pomc reporter activity induced by EGF was dose-dependently inhibited by U0126, but not by S31-201 (Figure 2E), which suggests that EGF induced Pomc transcriptional activity via MAPK. To determine the Pomc promoter regulatory elements required for EGF signaling, we generated truncated Pomc mutants with the pGL4 Basic luciferase expression vector. EGF treatment in EGFRWT transfectants showed that deletion of promoter bps 
A

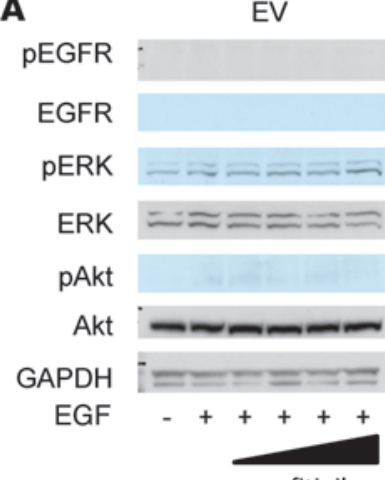

gefitinib
EGFRWT
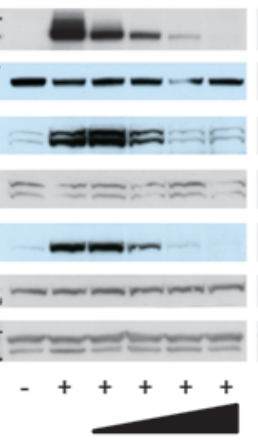

gefitinib

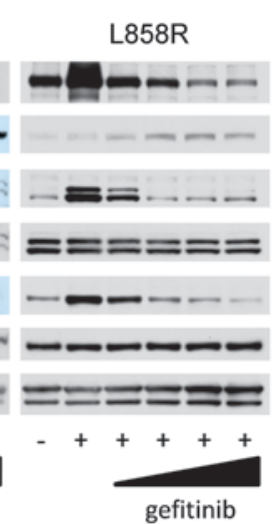

gefitinib

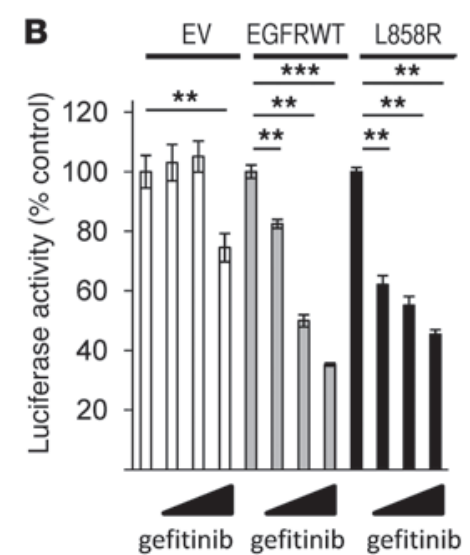

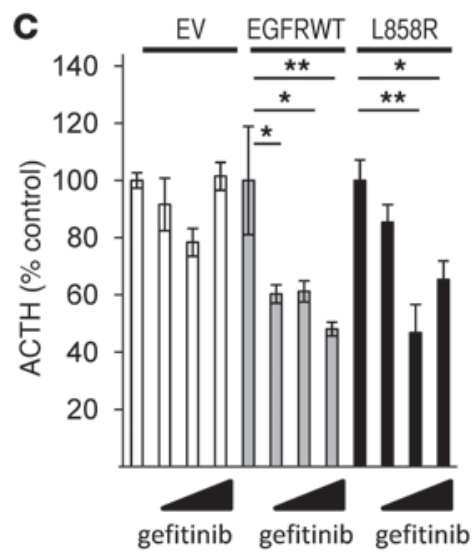

\section{Figure 3}

Gefitinib suppresses Pomc promoter activity and ACTH secretion. (A) EGFRWT, L858R, or EV cells were treated with gefitinib $(0.1-10 \mu \mathrm{M})$ for 45 minutes prior to induction with $5 \mathrm{nM}$ EGF for 10 minutes, and Western blotting was performed. (B) EGFRWT, L858R, or EV cells were transfected with Pomc promoter and RSV- $\beta$-gal for 24 hours. After 6 hours of serum deprivation, cells were treated with gefitinib $(0.1-10 \mu \mathrm{M})$ for 24 hours. (C) EGFRWT, L858R, or EV cells were treated with gefitinib $(0.1-10 \mu \mathrm{M})$ for 24 hours, and ACTH secretion was determined by RIA (normalized for cell numbers). Values are mean \pm SEM. ${ }^{\star} P<0.05,{ }^{* \star} P<0.01,{ }^{* \star} P<0.001$. Representative results are from triplicate samples in at least 2 independent experiments.

DNA synthesis in EGFR transfectants (EGFRWT, $\sim 10 \%, P<0.05$; L858R, $40 \%, P<0.01$; Figure 4E). Sensitivity to the drug was higher in mutants expressing L858R. Higher doses of drug $(10 \mu \mathrm{M})$ reduced BrdU incorporation, even in EV transfectants $(\mathrm{EV}, \sim 58 \%$, $P<0.01$; EGFRWT, $\sim 50 \%, P<0.01$; L858R, $70 \%$, $P<0.01$; Figure 4E), while cell number was not altered with the high dose in EV cells (Figure 4A).

We then analyzed effects of gefitinib on intracellular signaling molecules. Western blot results showed that gefitinib enhanced p27 expression $(\sim 1.4$-fold, $P<0.05)$ and attenuated levels of retinoblastoma protein (phospho-Rb) (Ser780), E2F1, and pituitary tumor transforming gene (PTTG) $(\sim 44 \%, P<0.05 ; \sim 50 \%, P<0.05$; and $\sim 18 \%, P<0.05$, respectively; Figure $4 \mathrm{~F})$.

-323 to $-200-$ which include both pituitary restricted transcription factor (Tpit) and paired-like homeodomain transcription factor 1 (Pitx1) responsive elements (RE) - abrogated EGF induction of Pomc (Figure 2F).

Gefitinib suppresses Pomc expression and ACTH secretion in murine corticotroph tumor cells. Next, we tested effects of blocking EGFR activity on hormone expression and secretion in AtT20 transfectants. First, we confirmed the blocking effects of gefitinib on EGFR downstream signaling in murine corticotroph tumor cells. Western blotting analysis showed that gefitinib dose-dependently suppressed EGF-induced phosphorylation of EGFR, ERK, and Akt in EGFRWT and L858R transfectants, but not in EV transfectants (Figure 3A). RIA and luciferase assay results showed that gefitinib attenuated Pomc promoter activity (EGFRWT, $\sim 63 \%, P<0.001$; L858R, $\sim 58 \%, P<0.01$ ) and ACTH secretion (EGFRWT, $\sim 60 \%$, $P<0.01$; L858R, $\sim 60 \%, P<0.01)$, while the highest gefitinib dose tested $(10 \mu \mathrm{M})$ suppressed Pomc promoter activity even in control cells $(\sim 23 \%, P<0.01$; Figure 3, B and C).

Gefitinib induces apoptosis and suppresses murine corticotroph tumor cell proliferation. We tested effects of gefitinib on murine corticotroph adenoma cell proliferation. Gefitinib decreased the number of EGFRWT $(\sim 65 \%, P<0.01)$ and L858R $(\sim 40 \%, P<0.01)$ cells, but not EV cells (Figure 4A). Gefitinib also dose-dependently reduced formation of colonies by these transfectants in soft agar $(\sim 60 \%, P<0.01$; Figure 4B). Furthermore, TUNEL staining showed that inhibition of EGFR kinase also induced apoptosis, while Western blot results showed elevated p53 and cleaved caspase 3 levels (Figure 4, C and D). Results of BrdU incorporation measurements showed that $1 \mu \mathrm{M}$ gefitinib treatment reduced
Nuclear EGFR function in corticotroph tumors. To further characterize EGFR expression in human and canine ACTH-producing pituitary tumors, we showed evidence for strong immunoreactive corticotroph tumor nuclear EGFR localization in both species. In contrast, both membranous and nuclear EGFR were detected in breast cancer specimens (positive control), while no EGFR staining was evident in testis (negative control) (Figure 5A). To elucidate the function of corticotroph tumor nuclear EGFR, we transiently transfected a nuclear-expressing EGFR construct, pCMV/EGFR$\mathrm{ICD} / \mathrm{myc} /$ nuc (referred to herein as ICD), and showed nuclear EGFR localization; in contrast, control pCMV/EGFR/myc/nuc transfectants were located mainly on AtT20 membranes and in the cytoplasm (Figure 5B). ICD overexpression in AtT20 cells induced ACTH secretion $(\sim 1.5$-fold, $P<0.05)$ and Pomc mRNA expression $(\sim 1.5$-fold, $P<0.01)$ that was not altered by WT EGFR overexpression (Figure 5, C and D). Thus, membrane EGFR overexpression appears to require ligand-dependent activation to induce ACTH secretion (Figure 2D). Next, we tested gefitinib action on nuclear EGFR signaling and showed suppressed Pomc expression in ICDoverexpressing AtT20 transfectants $(\sim 50 \%, P<0.05$; Figure $5 \mathrm{E})$.

In vivo effects of gefitinib on EGFR-overexpressing AtT20 allografts. To evaluate effects of gefitinib in vivo, EGFRWT or EV transfectants were inoculated s.c. into 7-week-old female nude mice (NU/J) randomized to receive either oral gefitinib $(100 \mathrm{mg} / \mathrm{kg} / \mathrm{d})$ or vehicle. Drug treatment was started 3 days after cell inoculation $\left(1 \times 10^{6}\right.$ cells/mouse). As shown in Figure 6, A and B, the EGFR-expressing tumors thus generated were larger than controls $(\sim 3$-fold, $P<0.01)$, and this tumor growth was inhibited by gefitinib treatment $(\sim 40 \%$, $P<0.01)$. Elevated serum corticosterone levels in the EGFR group 

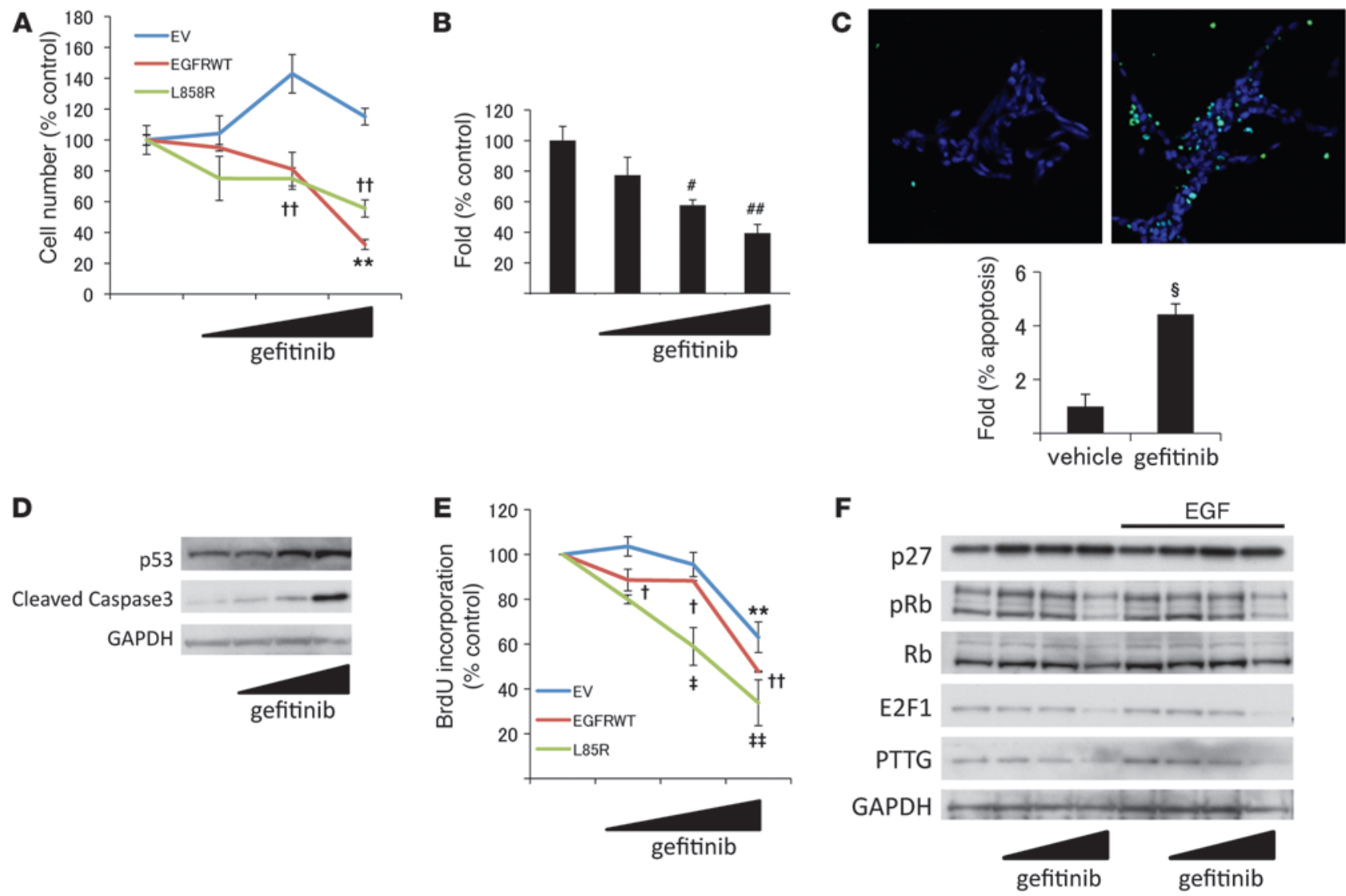

\section{Figure 4}

Effects of gefitinib on corticotroph adenoma cell proliferation. (A) EGFRWT, L858R, or EV cells were treated with gefitinib (0.1-10 $\mu$ M) for 24 hours, and cells were counted. (B) EGFRWT cells were seeded (4,000 cells/well) for colony-forming assay, and gefitinib (0.1-10 $\mu$ M) was added with serum-depleted media every third day. Colonies were counted from 5 randomly selected fields. (C) EGFRWT cells were treated with gefitinib $(0.1-10 \mu \mathrm{M})$ for 48 hours, and TUNEL staining was performed. Original magnification, $\times 20$. Apoptotic cells were counted from 5 randomly selected fields (normalized by DAPI-stained cell number). (D) EGFRWT cells were treated with gefitinib (0.1-10 $\mu \mathrm{M})$ for 48 hours, and Western blotting was performed. (E) EGFRWT, L858R, or EV cells were treated with gefitinib $(0.1-10 \mu \mathrm{M})$ for 24 hours, BrdU staining was performed, and incorporation was quantified using flow cytometry. (F) EGFRWT cells were treated with gefitinib $(0.1-10 \mu \mathrm{M})$ for 24 hours with or without EGF $(5 \mathrm{nM})$, and Western blotting was performed. Values are mean \pm SEM. ${ }^{*} P<0.01,{ }^{\# \#} P<0.01$ vs. untreated control; $\$ P<0.001$ vs. vehicle control; ${ }^{\star \star} P<0.01$ vs. EV control; ${ }^{\dagger} P<0.05,{ }^{\dagger \dagger} P<0.01$ vs. EGFRWT control; $¥ P<0.05,{ }^{\ddagger} P P<0.01$ vs. L858R control. Representative results are from triplicate samples in at least 2 independent experiments.

$(432 \pm 52 \mathrm{ng} / \mathrm{ml}$ vs. $186 \pm 12 \mathrm{ng} / \mathrm{ml} ; P<0.01)$ were also attenuated by oral gefitinib $(\sim 35 \%, P<0.05$; Figure $6 \mathrm{C})$. Mice injected with EGFR transfectants showed features of hypercortisolemia, including central fat accumulation, hyperglycemia, and weight gain, all of which were attenuated by oral gefitinib treatment (Figure 6, D-F). Notably, in mice injected with control AtT20 cells devoid of the EGFR, serum corticosterone, fat accumulation, glucose levels, and body weight were not altered by oral gefitinib treatment.

\section{Discussion}

Targeted medical therapy for ACTH-producing pituitary adenomas is one of the most important current challenges for treating patients harboring endocrine tumors. Here, we explored the role of EGFR in pituitary corticotroph tumors. In human Cushing tumors, gefitinib suppressed $P O M C$ expression by approximately $95 \%$, and these drug effects were confirmed using canine corticotroph adenoma cells. Canine pituitary-dependent hyperadrenocorticism (PDH) largely recapitulates Cushing disease in humans and is commonly encountered. Clinical signs are mostly similar to the human disease, including central obesity, ravenous appetite, polyuria, polydipsia, thin skin, distinctive "potbelly" appearance, and loss of hair (31). In the present study, inhibition of EGFR kinase activity in canine tumor cell cultures suppressed $80 \%$ of POMC expression and $75 \%$ of ACTH secretion. However, the observed normalization of in vitro ACTH secretion - to pretreatment levels - was not necessarily accurate, as cell disruption may release secreted granules resulting in higher medium ACTH measurements. Real-time PCR results, a more sensitive measure of POMC mRNA, were similarly suppressed by gefitinib. Tumor cells derived from dogs 1 and 2 did not respond to gefitinib and did not express EGFR, which suggests that hormone-suppressive effects of gefitinib in canine tumors are mediated by EGFR. Dog 11 showed the highest levels of EGFR expression, and the suppressive effect on POMC gene levels appeared strong. However, ACTH was not attenuated in the culture, possibly suggestive of cell disruption (29). 

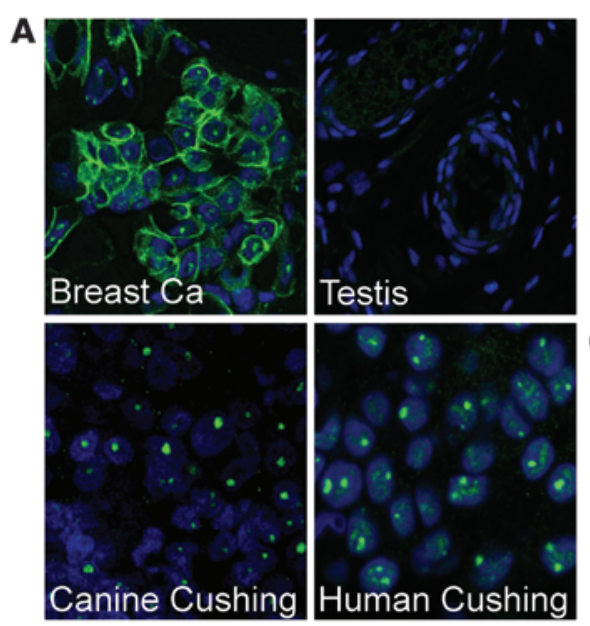

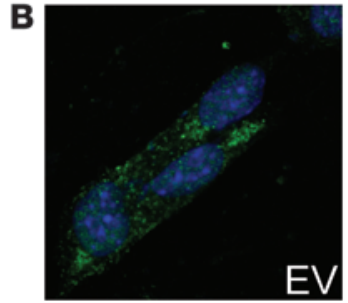

C

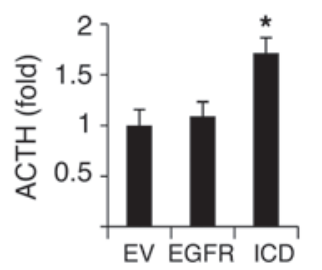

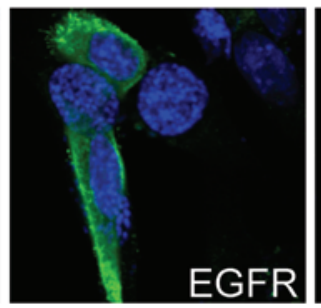

D

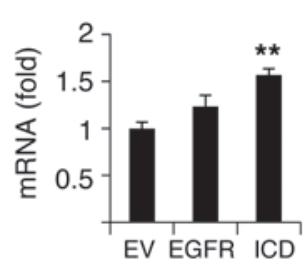

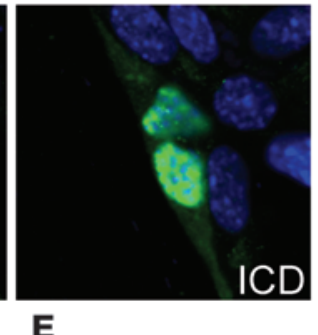

E

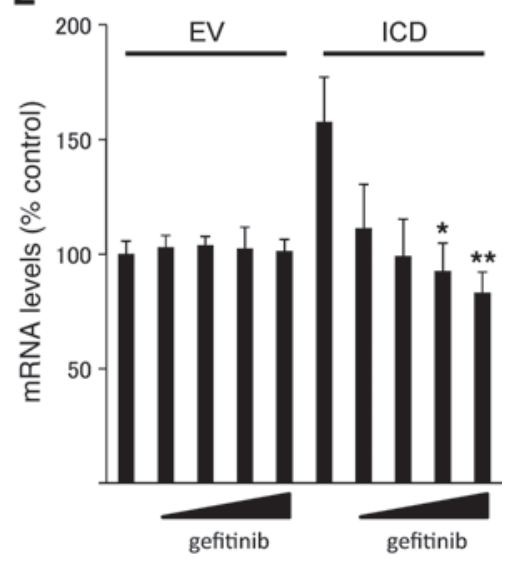

\section{Figure 5}

Nuclear EGFR localization in corticotroph adenomas. (A) Confocal immunocytochemistry for EGFR was performed in human and canine corticotroph tumors. Human breast cancer tissue was used as a positive control, and human testis as negative control, for EGFR expression. Original magnification, $\times 100$. (B-E) AtT20 cells were transiently transfected with EGFR (pCMV/EGFR/myc/nuc), ICD (pCMV/EGFR-ICD/myc/nuc), or EV (pCMV/myc/nuc) for 24 hours. (B) Immunofluorescent chemistry was performed with anti-EGFR. Original magnification, $\times 100$. (C) Media were changed to serum-depleted media and collected 24 hours later. ACTH levels in culture media were measured using RIA (normalized for cell numbers). (D) RNA was extracted, and mouse Pomc expression levels were measured by real-time PCR. A representative experiment is shown (normalized by Gapdh). (E) After gefitinib treatment for 24 hours, RNA was extracted, and mouse Pomc expression levels were measured by real-time PCR. A representative experiment is shown (normalized by Gapdh). Values are mean $\pm \mathrm{SEM}$. ${ }^{*} P<0.05$, ${ }^{* *} P<0.01$, vs. EV. Representative results are from triplicate samples in at least 2 independent experiments.

Pomc expression and ACTH secretion were clearly induced by EGF in an EGFR-dependent manner, and the Pomc promoter was also activated by EGFR signaling. Differentiated Pomc promoter activity is regulated by complex mechanisms subserved by several transcriptional factors, including nuclear receptor subfamily 4 (Nur), STAT3, neurogenic differentiation 1 (NeuroD1), Tpit, Pitx1, NF-кB, cAMP response element-binding protein (CREB), and glucocorticoid receptor (GR) (32-37). We elucidated the mechanisms underlying EGF induction of Pomc promoter activity and showed the MAPK dependence of EGFR signaling, which also required a -323 to -200 bp element that is proximal to the Pomc initiation site (downstream of MAPK) and includes tissuespecific Tpit/Pitx sites (38).

Gefitinib suppressed Pomc promoter activity and ACTH secretion in an EGFR-dependent manner. Gefitinib also induced apoptosis and inhibited AtT20 transfectant proliferation. Antiproliferative and proapoptotic effects of gefitinib have previously been shown in cells of non-small cell lung cancer (NSCLC), breast cancer, and prostate cancer $(30,39,40)$. In NSCLC, a somatic mutation of EGFR, L858R, renders tumors particularly sensitivity to gefitinib (29). In the present study, antiproliferative and antiapoptotic effects of gefitinib were more marked in L858R than in WT transfectants. On the other hand, hormone suppression by gefitinib in WT and L858R cells was not different. Although
EGFR mutations have not been detected in human Cushing tumors (18), further investigation is required to rigorously exclude putative mutations in these very rare and small tumors. The effects of gefitinib on cell cycle proteins and on apoptosis appeared to be weak. Nevertheless, cell number and BrdU incorporation were both attenuated by up to $60 \%$, reflecting the drug effects on tumor cell proliferation. More interestingly, gefitinib treatment apparently induced $\mathrm{p} 27^{\mathrm{kip} 1}$, a cyclin-dependent kinase inhibitor that is downregulated in most Cushing tumors (41, 42). Interestingly, mice lacking p 27 developed Pomc-expressing murine pituitary tumors (19), and p27 germline mutations are associated with human corticotroph adenomas (43), suggestive of a key role for $\mathrm{p} 27$ depletion in corticotroph cell tumorigenesis. Roscovitine, a cyclin-dependent kinase inhibitor, has also been shown as a possible target for experimental corticotroph tumors in zebrafish and in murine allografts (44). Taken together, our results support the notion that blocking EGFR signaling could attenuate corticotroph adenoma growth and ACTH secretion.

Gefitinib effectively suppressed ACTH secretion and inhibited tumor growth in EGFR-expressing tumors in vivo, in support of the in vitro results. In mice inoculated with WT transfectants, attenuating effects of gefitinib on phenotypic features of hypercortisolism were paralleled by reductions in serum corticosterone levels, which indicates that gefitinib's effects are mediated by 

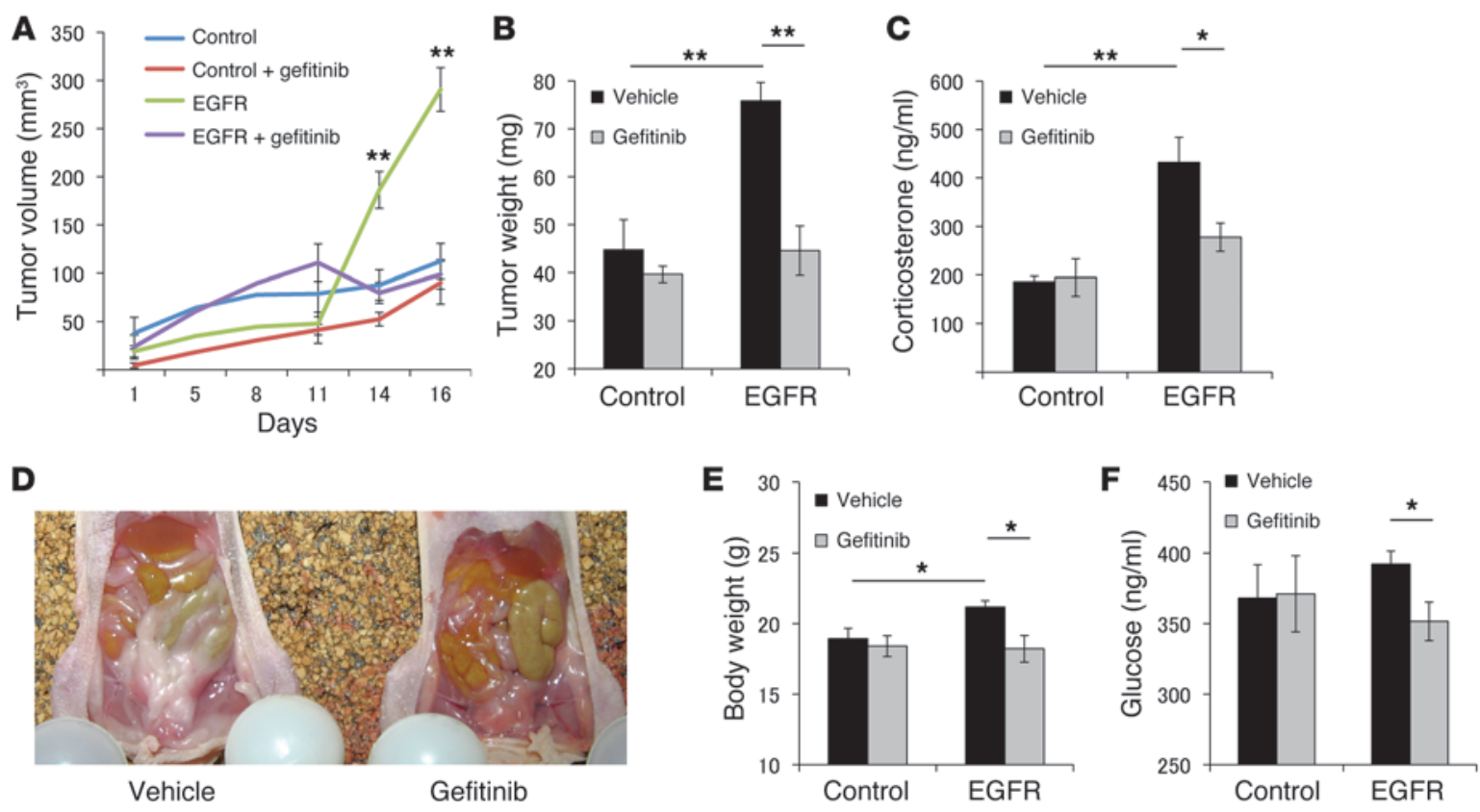

Figure 6

Gefitinib attenuates EGFR tumor growth and hormone secretion in vivo. EGFRWT $\left(1 \times 10^{6}\right.$ cells/mouse, $0.1 \mathrm{ml}$ with matrigel) or EV transfectants were injected s.c. in 7-week-old nude mice. 3 days after inoculation, mice with EGFR or control tumors received either vehicle $(0.5 \%$ methylcellose and $0.5 \%$ tween $80 /$ PBS) or gefitinib (100 mg/kg) for 10 days. (A) On the indicated days after treatment, tumor volume was measured by caliper and calculated as in Methods. (B) After euthanasia, tumors were excised and weighed. (C) Serum corticosterone levels were measured by RIA. (D) Omental fat was more prominent in EGFR-injected than control mice. Murine body weight (E) and plasma glucose levels (F) were measured after euthanasia. Values are mean \pm SEM. ${ }^{*} P<0.05 ;{ }^{*} P<0.01$.

tumoral hormone suppression. Although EGFR has previously been shown to regulate adrenal steroidogenesis (45), we showed here that serum corticosterone levels were attenuated by gefitinib only in animals with EGFR-expressing pituitary tumors, which suggests that gefitinib's effect was primarily mediated by corticotroph tumor EGFR signal regulation.

Using immunofluorescence, we detected nuclear EGFR expression in both canine and human Cushing tumors. Nuclear EGFR localization has previously been reported in breast, ovarian, and thyroid cancers (46-48), likely as a result of ligand-dependent EGFR nuclear translocation (49). Nuclear EGFR may act as a transcription factor (50) and directly induce proliferating cell nuclear antigen (PCNA) phosphorylation (51). Nuclear EGFR also confers drug resistance to cetuximab, a monoclonal EGFR antibody (52). Our results showed that nuclear EGFR selectively induced Pomc expression and ACTH secretion in AtT20 cells. Since both human and canine ACTHsecreting pituitary adenomas expressed nuclear EGFR, it will be important to understand its function, even though the effect on $P O M C$ expression was modest. More importantly, gefitinib suppressed ACTH secretion in nuclear EGFR-expressing corticotroph tumor cells. This is especially relevant for future application of the drug as a therapy for patients with Cushing disease, as these tumors express nuclear EGFR. We previously showed the efficacy of TKIs for prolactinomas, which also express nuclear EGFR (15).

The results show that EGFR signaling induced Pomc mRNA expression and ACTH secretion in corticotroph tumors. Blocking receptor tyrosine activity with gefitinib suppressed ACTH secretion and corticotroph growth both in vitro and in vivo. As gefitinib attenuated nuclear EGFR induction of Pomc expres- sion, either membranous or nuclear EGFR could be a molecular target for treating patients with Cushing disease. Validating the clinical impact of gefitinib on canine and human Cushing tumors requires appropriately controlled clinical trials.

\section{Methods}

Materials. DMEM and penicillin/streptomycin were purchased from Invitrogen. EGF was from Sigma. Gefitinib (Iressa) was purchased from LC Laboratories.

Plasmid constructs. The various deletion mutant of rat Pomc promoter containing $-379 /+63,-323 /+63,-200 /+63,-155 /+63,-100 /+63$, and $-34 /+63$ were cloned by PCR from a previously described reporter plasmid (33) using specific primers; digested with Sal1 and BamH1; subcloned into pGL4.10 vector (Promega); and digested with XhoI and BglII. pRL-TK and RSV- $\beta$-gal vectors were purchased from Promega. For nuclear EGFR expression, the intracellular domain of EGFR (1,988-3,633 bp) was cloned by PCR from the pcDNA3.1-EGFRWT construct (gift of M.I. Greene, University of Pennsylvania, Philadelphia, Pennsylvania, USA) and subcloned into the empty $\mathrm{pCMV} / \mathrm{myc} /$ nuc vector (Invitrogen), both of which were digested with NcoI and NotI. As a control, full-length EGFR was subcloned into the $\mathrm{pCMV} / \mathrm{myc} /$ nuc vector, which confirmed expression of EGFR as a membrane protein. All constructs were verified by sequencing.

Stable cell transfections. AtT20 murine corticotroph tumor cells secreting ACTH were purchased from ATCC. EV, EGFRWT, or L858R cells were generated by retroviral infection containing EGFRWT cDNA, L858R cDNA, or EV (pBABEpuro, plasmid 11011 and 11012; Addgene), respectively. Stable colonies were selected in the presence of $100 \mathrm{ng} / \mathrm{ml}$ puromycin (SigmaAldrich) for pBABEpuro vector. A vector control cell line (pBABEpuro) was simultaneously established by transfecting each vector devoid of respective 
inserted cDNA. After selection and propagation, stable transfectants were cultured in DMEM containing 10\% FBS, penicillin/streptomycin, and 100 $\mathrm{ng} / \mathrm{ml}$ puromycin. After synchronization by serum starvation (medium containing $1 \%$ FBS for $\sim 16$ hours), cells with treatment agents were grown in fresh serum-depleted medium (1\% FBS), and samples were collected at the indicated times.

Northern blotting. Probes for murine Pomc were generated as described previously (53). $\beta$-actin probe was a $1,076-\mathrm{kb}$ fragment of the mouse $\beta$-actin gene (Ambion). RNA extraction was performed using TRIzOL reagent (Invitrogen) according to the manufacturer's instructions. For Northern blot analysis, 10-20 $\mu \mathrm{g}$ of total RNA was electrophoresed on $1 \%$ agarose, $6.4 \%$ formaldehyde gel; transferred to Hybond- + membrane (Amersham); and UV cross-linked. Probes were labeled with $(\alpha-32 \mathrm{P}) \mathrm{CTP}$ using the Primeit random primer labeling kit (Stratagene). Micro Bio-Spin chromatography columns (Bio-Rad) were used to purify probes. Membrane prehybridization and hybridization were performed using QuickHyb Solution (Stratagene) and then exposed to Hyperfilm MP (Amersham) for 1-4 days at $-70^{\circ} \mathrm{C}$.

Real-time RT-PCR. Total RNA was extracted with TRIzOL reagent (Invitrogen) according to the manufacturer's instructions. RNA quantification and integrity were assessed by measurement of absorbance at 260 and $280 \mathrm{~nm}$. Total RNA was reverse transcribed into first-strand cDNA using iScript cDNA synthesis kit (Bio-Rad Laboratories Inc.) according to the manufacturer. Quantitative PCR reactions were carried out using a iQ5 Multicolor Real-time PCR Detection System (Bio-Rad Laboratories Inc.), as described previously (54). Certified $\mathrm{RT}^{2}$ primer assays for mouse Pomc and human $P O M C$ were purchased from SuperArray. The human housekeeping gene primer set was from Real-time Primers, including GUSB, $A C T B, G A P D H$, and $R L P 13 A$, as described previously (55). Primer sequences (Invitrogen) were as follows: mouse $18 s$ rRNA forward, 5 '-GGACATCTAAGGGCATCACA-3'; mouse $18 s$ rRNA reverse, 5'-TCAAGAACGAAAGTCGGAGG-3'; mouse Gapdh forward, 5'-CTGGAGAAACCTGCCAAGTA-3'; mouse Gapdh reverse, 5'-TGTTGCTGTAGCCGTATTCA-3'; canine POMC forward, 5'-GGCCTCTGTGGAAGTGAGTG-3'; canine POMC reverse, 5'-ACGCCAGCAGGTTACTTTCC-3'; canine GUS forward, 5'-CCTCCTGCCGTATTACCCTTG-3'; canine GUS reverse, 5' -TCTGGACGAAGTAACCCTTGG-3'; canine RPS5 forward, 5'-TCACTGGTGAGAACCCCCT-3'; canine RPS5 reverse, 5'-CCTGATTCACACGGCGTAG-3'; canine GAPDH forward, 5'-GATGGGCGTGAACCATGAG-3'; canine GAPDH reverse, 5'-TCATGAGGCCCTCCACGAT-3'.

TaqMan PCR. TaqMan Gene Expression Assays for canine EGFR (cEGFR, cf02626541_m1) were purchased from Applied Biosystems. Amplicons were detected using relevant probes tagged with MGB quencher and FAM dye. TaqMan canine $\beta$-ACTIN control Expression Assays with probe tagged with MGB and VIC (Applied Biosystems) were used as reference gene. Real-time PCR was carried out in a MicoAmp Optical 96-well plate in ABI Prism 7700 Sequence Detector (Applied Biosystems) as described previously (56). Tested sample signals were normalized to parallel values obtained for $\beta$-ACTIN.

Western blotting. After treatments, cells were placed on ice and washed with cold PBS. For protein extraction, cells were lysed in $100 \mu \mathrm{l}$ of Radio Immuno Precipitation Assay (RIPA) buffer (Sigma-Aldrich) containing complete protease inhibitor cocktail tablets (Roche Molecular Biochemicals) and phosphatase inhibitor cocktail 2 (Sigma-Aldrich). Lysates were centrifuged at $13,000 \mathrm{~g}$ for 10 minutes at $4^{\circ} \mathrm{C}$, and protein concentrations were determined by BCA protein assay reagent (Thermo Scientific). Western blot analysis was performed according to the guidelines of NuPAGE electrophoresis system protocol (Invitrogen). In brief, whole cell lysates $\left(\sim 50 \mu \mathrm{g}\right.$ protein per lane) were heated for 5 minutes at $100^{\circ} \mathrm{C}$. Proteins were separated on $4 \%-12 \%$ NuPAGE Bis-Tris gels and electrotransferred for 1 hour to polyvinylidene difluoride (Invitrogen). Membranes were blocked for 1 hour in 5\% nonfat dry milk or 5\% BSA in TBS-T buffer and incubated overnight with primary antibodies, including anti-pErk $1 / 2$, anti-Erk $1 / 2$, anti-Akt, anti-pEGFR (Tyr1068), anti-EGFR, anti-caspase3, and anti-phospho-Rb (Ser780) from Cell Signaling Technology; anti-p53, anti-p27, anti$\mathrm{Rb}$, anti-E2F1, and anti-GAPDH from Santa Cruz Biotechnology; and anti-pAkt (Ser473) and anti-pttg from Abcam. After washing with TBS-T, membranes were incubated with peroxidase-conjugated secondary antibody for 1 hour (5\% nonfat dry milk or 5\% BSA in TBS-T buffer). Blots were washed, and hybridization signals were measured by enhanced chemiluminescence detection system (Amersham).

Soft agarose colony-forming assay. Base layers consisting of growth medium containing $0.6 \%$ low-melting point agarose (Invitrogen) were poured onto 6-well plates and allowed to solidify. Cells $\left(8 \times 10^{3}\right.$ per well $)$ were plated in triplicate in the top layers consisting of growth medium containing $0.3 \%$ agarose. $7-10$ days later, cells were stained with $0.2 \%$ iodonitrotetrazolium chloride (Invitrogen), and colonies containing 50 or more cells were counted manually in 5 randomly selected fields.

Cell proliferation assay. EGFRWT cells were plated at a density of $2 \times 10^{4}$ per well in 12 -well plates with growth medium. Cells were counted by hemocytometer at the indicated times.

BrdU incorporation. BrdU incorporation was measured by 5-Bromo-2'deoxy-uridine Labeling and Detection Kit II (catalog no. 11299964 001; Roche). Cells were plated at a density of $8 \times 10^{5}$ cells per $10-\mathrm{cm}$ dish in serum-supplemented media and allowed to attach. Cells were starved overnight in $1 \%$ FBS media, treated with gefitinib for 24 hours, and incubated in media containing $10 \mu \mathrm{M} \mathrm{BrdU}$ for 1 hour. Fixative was prepared by adding $30 \mathrm{ml}$ of $50 \mathrm{mM}$ glycine solution ( $\mathrm{pH} 2.0$ ) to $70 \mathrm{ml}$ ethanol. Cells were fixed overnight at $-20^{\circ} \mathrm{C}$, washed with PBS, and resuspended in incubation solution with anti-BrdU antibody (1:10 dilution) for 30 minutes at $37^{\circ} \mathrm{C}$ with gentle agitation. Cells were washed with PBS and resuspended in 100 $\mu \mathrm{l}$ of $1 \%$ BSA/PBS with anti-mouse Alexa Fluor 488-conjugated secondary antibody (1:250 dilution) and incubated for 1.5 hours in the dark. Samples were washed with PBS, and fluorescence was measured by flow cytometry.

TUNEL assay. Cells were plated at a density of $5 \times 10^{4}$ cells per well in serum-supplemented media and allowed to attach on poly-D-lysine-coated glass slides in 12-well plates. Cells were starved overnight in DMEM with $1 \%$ FBS, then treated with gefitinib for 24 hours, fixed for 2 hours by $4 \%$ paraformaldehyde in PBS, and permeabilized by $0.1 \%$ TritonX-100 in $0.1 \%$ sodium citrate. $100 \mu \mathrm{l}$ of label solution/enzyme solution mixture was added to cells and incubated at $37^{\circ} \mathrm{C}$ for 1 hour. Washed samples were mounted and observed under confocal microscopy.

Hormone assays. RIAs for mouse ACTH and mouse corticosterone were performed in duplicate using reagents purchased from MP Biomedicals according to the manufacturer's instructions.

Cultures of canine or buman ACTH-producing pituitary tumor-derived cells. Canine (VCA West Los Angeles Animal Hospital) or human (CedarsSinai Medical Center, Pituitary Center) ACTH-producing tumor tissues were obtained at the time of surgery and transferred in $0.3 \%$ BSA-containing DMEM. After washing, tumor tissues were chopped with a sterile scalpel into approximately 1 - to 2 -mm pieces, rinsed, and digested with DMEM containing $0.3 \%$ BSA, $0.35 \%$ collagenase, and $0.15 \%$ hyaluronidase at $37^{\circ} \mathrm{C}$ for 30 minutes. The mixture was centrifuged at $350 \mathrm{~g}$ for 5 minutes at $4^{\circ} \mathrm{C}$, and the cell pellet was resuspended in culture medium containing $10 \%$ FBS and antibiotics in 48 -well plates. After 24 hours of incubation with serum-depleted starvation medium (DMEM with $0.3 \%$ BSA), treatment agents were added with fresh serum-depleted medium ( $0.3 \% \mathrm{BSA})$, and medium was collected for RIA. RNA was extracted after 24 hours of treatment. Medium ACTH concentrations were normalized by the measured concentrations of pretreatment ACTH. The diagnosis of PDH was based on the presence of typical clinical signs and confirmed by measurement of basal ACTH concentrations, urine cortisol to creati- 
nine ratio (UCCR), and performance of either the low-dose dexamethasone suppression test (LDDS) and/or an ACTH stimulation test. For the LDDS, a diagnosis of hyperadrenocorticism was based on failure to suppress cortisol concentrations to below $1.4 \mu \mathrm{g} / \mathrm{dl}$ at 8 hours. A UCCR - derived from the first morning, voided urine sample - greater than 13 was considered abnormal. The ACTH stimulation test was performed by collecting serum samples prior to and 1 hour after i.m. or i.v. administration of $5 \mu \mathrm{g} / \mathrm{kg}$ synthetic ACTH (Cortrosyn). A post-ACTH cortisol level greater than $22 \mu \mathrm{g} / \mathrm{dl}$ was considered diagnostic for hyperadrenocorticism. PDH was confirmed by measurement of endogenous ACTH concentrations and/or greater than 50\% suppression of serum cortisol concentrations during the course of the LDDS. Endocrine assays were performed at a commercial clinical veterinary laboratory with established normalized values (Antech Diagnostics).

Immunofluorescence. Tumor specimens were fixed in $10 \%$ formalin and embedded in paraffin. After deparaffinization and antigen retrieval, slides were blocked in $10 \%$ goat serum in $1 \%$ BSA-PBS and then incubated overnight with rabbit polyclonal anti-EGFR (sc-03, 1:50 dilution; Santa Cruz). After washes, slides were incubated with Alexa Fluor goat anti-rabbit 488 $(\mathrm{H}+\mathrm{L}, 1: 500$ dilution; Invitrogen) and Topro3 (Invitrogen) for 2 hours at room temperature, then mounted with Prolong Gold antifade reagent (Invitrogen). Confocal microscope images were obtained using True Confocal Scanner (TCS-SP) confocal scanner (Leica Microsystems) in a dualemission mode to separate autofluorescence from specific staining.

Animals. Six- to eight-week-old female $\mathrm{Nu} / \mathrm{J}$ (Harlan Sprague Dawley) were inoculated with EV or EGFRWT stable transfectants $\left(1 \times 10^{6}\right.$ cells/ group). Tumor volumes were measured with a caliper and calculated as $\pi / 6 \times$ large diameter $\times$ small diameter ${ }^{2}$, as previously described (54). 3 days after inoculation, mice with EV or EGFRWT were divided into 2 groups $(n=10$ per group) and treated with gefitinib $(100 \mathrm{mg} / \mathrm{kg})$ or vehicle $(0.5 \%$ methylcellose, $0.5 \%$ tween $80 / \mathrm{PBS} ; 100 \mu \mathrm{l}$ ) by oral gavage daily for 10 days. On the last treatment day (day 10), mice were euthanized using $\mathrm{CO}_{2}$ inhalation followed by decapitation. Cardiac blood was collected with 18-gauge syringes, and tumors were excised and weighed.

Statistics. Results are expressed as mean \pm SEM. Differences were assessed by 1 -way ANOVA following Scheffe $F$ test. A $P$ value less than 0.05 was considered significant.

Study approval. This study was approved by the Institutional Animal Care and Use Committee and Institutional Review Board of Cedars-Sinai Medical Center and the Institutional Review Board of VCA West Los Angeles Animal Hospital. Informed consent was obtained from human subjects.

\section{Acknowledgments}

We thank Jun Mizutani for technical assistance, James Mirocha at the Cedars Sinai Biostatistics Core, Patricia Lin at the Flow Cytometry Core, Kolja Wawrowsky at the Imaging Core, S.I. Bannykh for provision of human slides, and Yukiko Tone, Masahide Tone, and Mark I. Greene for helpful discussions. This work was supported by NIH grants CA07597 (to S. Melmed) and K23DK085148-01 (to O. Cooper) and by the Doris Factor Molecular Endocrinology Laboratory.

Received for publication August 11, 2011, and accepted in revised form October 18, 2011.

Address correspondence to: Shlomo Melmed, Academic Affairs, Room 2015, Cedars-Sinai Medical Center, 8700 Beverly Blvd., Los Angeles, California 90048, USA. Phone: 310.423.4691; Fax: 310.423.0119; E-mail: Melmed@csmc.edu.
1. Melmed S. Mechanisms for pituitary tumorigenesis: the plastic pituitary. J Clin Invest. 2003; 112(11):1603-1618.

2. Newell-Price J, Bertagna X, Grossman AB, Nieman LK. Cushing's syndrome. Lancet. 2006; 367(9522):1605-1617.

3. Biller BM, et al. Treatment of adrenocorticotropindependent Cushing's syndrome: a consensus statement. J Clin Endocrinol Metab. 2008;93(7):2454-2462.

4. Tritos NA, Biller BM, Swearingen B. Management of Cushing disease. Nat Rev Endocrinol. 2011;7(5):279-289.

5. Jehle S, Walsh JE, Freda PU, Post KD. Selective use of bilateral inferior petrosal sinus sampling in patients with adrenocorticotropin-dependent Cushing's syndrome prior to transsphenoidal surgery. J Clin Endocrinol Metab. 2008;93(12):4624-4632.

6. Dwyer AJ, et al. Pituitary adenomas in patients with Cushing disease: initial experience with GdDTPA-enhanced MR imaging. Radiology. 1987; 163(2):421-426

7. Oldfield EH, et al. Petrosal sinus sampling with and without corticotropin-releasing hormone for the differential diagnosis of Cushing's syndrome. N Engl J Med. 1991;325(13):897-905.

8. Patronas $\mathrm{N}$, et al. Spoiled gradient recalled acquisition in the steady state technique is superior to conventional postcontrast spin echo technique for magnetic resonance imaging detection of adrenocorticotropin-secreting pituitary tumors. J Clin Endocrinol Metab. 2003;88(4):1565-1569.

9. Boscaro M, et al. Treatment of pituitary-dependent Cushing's disease with the multireceptor ligand somatostatin analog pasireotide (SOM230): a multicenter, phase II trial. J Clin Endocrinol Metab. 2009;94(1):115-122.

10. Pivonello R, et al. The medical treatment of Cushing's disease: effectiveness of chronic treatment with the dopamine agonist cabergoline in patients unsuccessfully treated by surgery. J Clin Endocrinol Metab. 2009;94(1):223-230.

11. Melmed S. Acromegaly pathogenesis and treatment. J Clin Invest. 2009;119(11):3189-3202.

12. Castillo V, et al. Retinoic acid as a novel medical therapy for Cushing's disease in dogs. Endocrinology. 2006;147(9):4438-4444.

13. Herbst RS. Review of epidermal growth factor receptor biology. Int J Radiat Oncol Biol Phys. 2004; 59(2 suppl):21-26.

14. Murdoch GH, Potter E, Nicolaisen AK, Evans RM, Rosenfeld MG. Epidermal growth factor rapidly stimulates prolactin gene transcription. Nature. 1982;300(5888):192-194.

15. Fukuoka H, et al. HER2/ErbB2 receptor signaling in rat and human prolactinoma cells: strategy for targeted prolactinoma therapy. Mol Endocrinol. 2011;25(1):92-103.

16. Onguru $\mathrm{O}$, et al. Analysis of epidermal growth factor receptor and activated epidermal growth factor receptor expression in pituitary adenomas and carcinomas. Mod Pathol. 2004;17(7):772-780.

17. LeRiche VK, Asa SL, Ezzat S. Epidermal growth factor and its receptor (EGF-R) in human pituitary adenomas: EGF-R correlates with tumor aggressiveness. J Clin Endocrinol Metab. 1996;81(2):656-662.

18. Theodoropoulou M, et al. Expression of epidermal growth factor receptor in neoplastic pituitary cells: evidence for a role in corticotropinoma cells. J Endocrinol. 2004;183(2):385-394.

19. Kiyokawa H, et al. Enhanced growth of mice lacking the cyclin-dependent kinase inhibitor function of p27(Kip1). Cell. 1996;85(5):721-732.

20. Nakayama K, et al. Mice lacking p27(Kip1) display increased body size, multiple organ hyperplasia, retinal dysplasia, and pituitary tumors. Cell. 1996;85(5):707-720.

21. Fero ML, et al. A syndrome of multiorgan hyperplasia with features of gigantism, tumorigenesis, and female sterility in p27(Kip1)-deficient mice. Cell. 1996;85(5):733-744.

22. Roussel-Gervais A, et al. Cooperation between cyclin E and p27(Kip1) in pituitary tumorigenesis. Mol Endocrinol. 2010;24(9):1835-1845.

23. Wang Q, Greene MI. Mechanisms of resistance to ErbB-targeted cancer therapeutics. J Clin Invest. 2008;118(7):2389-2392.

24. Mok TS, et al. Gefitinib or carboplatin-paclitaxel in pulmonary adenocarcinoma. $N$ Engl J Med. 2009;361(10):947-957.

25. Mellinghoff IK, et al. Molecular determinants of the response of glioblastomas to EGFR kinase inhibitors. N Engl J Med. 2005;353(19):2012-2024.

26. Cohen EE, et al. Phase II trial of gefitinib $250 \mathrm{mg}$ daily in patients with recurrent and/or metastatic squamous cell carcinoma of the head and neck. Clin Cancer Res. 2005;11(23):8418-8424.

27. Castillo VA, Gallelli MF. Corticotroph adenoma in the dog: pathogenesis and new therapeutic possibilities. Res Vet Sci. 2010;88(1):26-32.

28. Meij BP. Hypophysectomy as a treatment for canine and feline Cushing's disease. Vet Clin North Am Small Anim Pract. 2001;31(5):1015-1041.

29. Paez JG, et al. EGFR mutations in lung cancer: correlation with clinical response to gefitinib therapy. Science. 2004;304(5676):1497-1500.

30. Tracy S, Mukohara T, Hansen M, Meyerson M, Johnson BE, Janne PA. Gefitinib induces apoptosis in the EGFRL858R non-small-cell lung cancer cell line H3255. Cancer Res. 2004;64(20):7241-7244.

31. Kemppainen RJ, M EP. Animal models of Cushing's disease. Trends Endocrinol Metab. 1994;5(1):21-28.

32. Kovalovsky D, et al. Activation and induction of NUR77/NURR1 in corticotrophs by CRH/cAMP: involvement of calcium, protein kinase A, and MAPK pathways. Mol Endocrinol. 2002;16(7):1638-1651.

33. Bousquet C, Zatelli MC, Melmed S. Direct regulation of pituitary proopiomelanocortin by 
STAT3 provides a novel mechanism for immunoneuroendocrine interfacing. J Clin Invest. 2000; 106(11):1417-1425.

34. Jenks BG. Regulation of proopiomelanocortin gene expression: an overview of the signaling cascades, transcription factors, and responsive elements involved. Ann N Y Acad Sci. 2009;1163:17-30.

35. Poulin G, Turgeon B, Drouin J. NeuroD1/beta2 contributes to cell-specific transcription of the proopiomelanocortin gene. Mol Cell Biol. 1997;17(11):6673-6682.

36. Lamolet B, et al. A pituitary cell-restricted $\mathrm{T}$ box factor, Tpit, activates POMC transcription in cooperation with Pitx homeoproteins. Cell. 2001;104(6):849-859.

37. Karalis KP, Venihaki M, Zhao J, van Vlerken LE, Chandras C. NF-kappaB participates in the corticotropin-releasing, hormone-induced regulation of the pituitary proopiomelanocortin gene. J Biol Chem. 2004;279(12):10837-10840.

38. Maira M, Couture C, Le Martelot G, Pulichino AM, Bilodeau S, Drouin J. The T-box factor Tpit recruits SRC/p160 co-activators and mediates hormone action. J Biol Chem. 2003;278(47):46523-46532.

39. Moon DO, Kim MO, Heo MS, Lee JD, Choi YH, Kim GY. Gefitinib induces apoptosis and decreases telomerase activity in MDA-MB-231 human breast cancer cells. Arch Pharm Res. 2009;32(10):1351-1360.

40. Festuccia C, et al. Molecular aspects of gefitinib antiproliferative and pro-apoptotic effects in
PTEN-positive and PTEN-negative prostate cancer cell lines. Endocr Relat Cancer. 2005;12(4):983-998.

41. Lidhar K, et al. Low expression of the cell cycle inhibitor $\mathrm{p} 27 \mathrm{Kip} 1$ in normal corticotroph cells, corticotroph tumors, and malignant pituitary tumors. J Clin Endocrinol Metab. 1999;84(10):3823-3830.

42. Bamberger CM, et al. Reduced expression levels of the cell-cycle inhibitor $\mathrm{P} 27 \mathrm{Kip} 1$ in human pituitary adenomas. Eur J Endocrinol. 1999;140(3):250-255.

43. Georgitsi M, et al. Germline CDKN1B/p27Kip1 mutation in multiple endocrine neoplasia. J Clin Endocrinol Metab. 2007;92(8):3321-3325.

44. Liu NA, et al. Targeting zebrafish and murine pituitary corticotroph tumors with a cyclin-dependent kinase (CDK) inhibitor. Proc Natl Acad Sci U S A. 2011;108(20):8414-8419.

45. Carbajal L, Biswas A, Niswander LM, Prizant H, Hammes SR. GPCR/EGFR cross talk is conserved in gonadal and adrenal steroidogenesis but is uniquely regulated by matrix metalloproteinases 2 and 9 in the ovary. Mol Endocrinol. 2011; 25(6):1055-1065.

46. Lo HW, Xia W, Wei Y, Ali-Seyed M, Huang SF, Hung MC. Novel prognostic value of nuclear epidermal growth factor receptor in breast cancer. Cancer Res. 2005;65(1):338-348.

47. Marti $U$, et al. Nuclear localization of epidermal growth factor and epidermal growth factor receptors in human thyroid tissues. Thyroid. 2001;11(2):137-145.
48. Xia W, et al. Nuclear expression of epidermal growth factor receptor is a novel prognostic value in patients with ovarian cancer. Mol Carcinog. 2009;48(7):610-617.

49. Lo HW, et al. Nuclear interaction of EGFR and STAT3 in the activation of the iNOS/NO pathway. Cancer Cell. 2005;7(6):575-589.

50. Lin SY, et al. Nuclear localization of EGF receptor and its potential new role as a transcription factor. Nat Cell Biol. 2001;3(9):802-808.

51. Wang SC, et al. Tyrosine phosphorylation controls PCNA function through protein stability. Nat Cell Biol. 2006;8(12):1359-1368.

52. Li C, Iida M, Dunn EF, Ghia AJ, Wheeler DL. Nuclear EGFR contributes to acquired resistance to cetuximab. Oncogene. 2009;28(43):3801-3813.

53. Heaney AP, Fernando M, Yong WH, Melmed S. Functional PPAR-gamma receptor is a novel therapeutic target for ACTH-secreting pituitary adenomas. Nat Med. 2002;8(11):1281-1287.

54. Vlotides G, Siegel E, Donangelo I, Gutman S, Ren SG, Melmed S. Rat prolactinoma cell growth regulation by epidermal growth factor receptor ligands. Cancer Res. 2008;68(15):6377-6386.

55. Vlotides G, Cooper O, Chen YH, Ren SG, Greenman $\mathrm{Y}$, Melmed S. Heregulin regulates prolactinoma gene expression. Cancer Res. 2009;69(10):4209-4216.

56. Ben-Shlomo A, et al. Constitutive somatostatin receptor activity determines tonic pituitary cell response. Mol Endocrinol. 2009;23(3):337-348. 